\title{
STRATEGIES OF REDUCTION OF ABSTRACTION IN ABSTRACT ALGEBRA
}

\author{
Ruma Manandhar (PhD) ${ }^{1}$ 间 (iD), Prof. Lekhnath Sharma (PhD) ${ }^{2}$ \\ ${ }^{1}$ Assistant Professor, Nepal Open University, Nepal \\ ${ }^{2}$ Nepal Open University, Nepal
}

DOI: https://doi.org/10.29121/granthaalayah.v8.i11.2020.2446

Article Type: Research Article

Article Citation: Ruma Manandhar (PhD), and Prof. Lekhnath Sharma (PhD). (2020). STRATEGIES OF REDUCTION OF ABSTRACTION IN ABSTRACT ALGEBRA. International Journal of Research -

GRANTHAALAYAH, 8(11), 245-250. https://doi.org/10.29121/granthaa layah.v8.i11.2020.2446

Received Date: 10 November 2020

Accepted Date: 30 November 2020

Keywords:

Abstract Algebra

Ethnography

Mathematics

Process-Object Duality

Reduction

Strategies

\section{ABSTRACT}

This article is based on the study, which tries to unpack strategies of reduction of abstraction in learning abstract algebra from learners' perspective. Ethnography was used to collect the required information. The study found the strategies of reduction of abstraction in abstract algebra are: making sense and meaning through previous experiences and existing knowledge an analogical creation of mental image, using first person language in course of doing mathematics by students as teachers do in the classroom for logical arguments, focusing on "symbol" or some mathematical entity to manage abstraction for their idiosyncratic understandings of abstract mathematical structure rather than the reflective thinking, using students own idiosyncratic figures to reduce the degrees of complexity of mathematical concepts. This study can lead teachers of abstract algebra to a new awareness of their teaching strategies and their practices.

\section{INTRODUCTION}

Abstract algebra is universal in a sense that other fields of human thoughts are not because of its level of abstraction. Usually, abstract pattern studied by mathematicians for their own sake, have turned out much later to be very useful in science. Abstract algebra discovers general patterns and relationships, so in this sense, it is as a part of scientific endeavor and relies on both logic and creativity. The symbolic language of abstract algebra has turned out to be extremely valuable for expressing scientific ideas unambiguously, and therefore abstract algebra got space in the most of the higher education disciplines.

Abstraction in mathematics learning has been a frequent discussing topic since the days of Aristotle and Plato. Constructivist theories often espouse the notion of levels of abstraction (Mitchel\& White, 2007). It is still a perennial question in the field of learning abstract mathematics in higher education. In an educational context the encounter with mathematical abstraction is the crucial step of the transition from informal school mathematics to the formalism of university mathematics (Nardi,1996). Indeed, it is in the abstract algebra course that students are asked, for the first time, to deal with concepts which can introduce abstractly (Dubinsky \& Leron, 1994, p.42).

(C) 2020 The Author(s). This is an open access article distributed under the terms of the Creative Commons Attribution License, which permits unrestricted use, distribution, and reproduction in any medium, provided the original author and source are credited. 
Strategies of Reduction of Abstraction in Abstract Algebra

My own experiences as an Abstract Algebra teacher of undergraduate and graduate students in Nepal motivated me for this study. Researches on how higher mathematics learning could be facilitated to the students have not been conducted in Nepalese context yet. Then, I analyze and unfold how mathematicians' ways of learning mathematics can be reconstructed from an andragogical perspective. My ultimate aim is to understand how learning of higher mathematics could be facilitated to the students in Nepalese context.

\section{OBJECTIVE AND RESEARCH QUESTION OF THE STUDY}

Learning of abstract algebra by undergraduate students was analyzed on the basis of cognitive learning theories. Dubinsky et.al (1994), Asila et.al (1996,1997), Edward \& Brenton (1996), Brown et.al (1997), Findell (2001), Mingus (2001), Fukuwa-connelly (2007), Hirsch (2008) have done experimental studies in explaining the learning of abstract algebra. Specially, Hazzan (1999) did broader study to reduce the abstraction level in order to cope with the task at hand. Similarly, leron and Hazzan (1997) studied on coping mechanism and lack of using reflective thinking in the process of learning theorems in abstract algebra. Some of the aforementioned studies have utilized technology as tools for making meaningful understanding. The present study is however different than those, for it is based on traditional classroom setting with no computer assisted teaching in Nepalese context. The lack of development and awareness and an attention to structure in the learning of abstraction make students unable to use mathematics meaningfully when solving real problems (Novotna \& Hoch, 2008). So, the objective of the study was: to find strategies of reduction of abstraction in understanding abstract algebra from learners' perspective.

The research question of the study was as follows:

How could the students manage learning abstraction in abstract algebra?

\section{THEORETICAL FRAMEWORK}

The conceptual framework of the study was built on the Hazzan's Framework: Reducing Abstraction (Hazzan,1999). Hazzan's reducing abstraction framework is a specific framework for cognitive research and curriculum development of collegiate mathematics. From this perspective, most responses and conceptions on the part of students can be attributed to their tendency to work on a lower level of abstraction than the one in which concepts are introduced in class. The mental process of reducing abstraction level indicates that students' find ways to cope with new concepts from what they already learned. Students make these concepts mentally accessible, so that they would be able to think with them and handle them cognitively. There are three interpretations for level of abstractions which are as follow:

1) Abstraction level as the quality of the relationships between the object of the thought and the thinking person: For each concept and for each person we may observe a different level of abstraction which reflects previous experimental connection between the two. The closer a person is to an object and the more connections s/he has formed to it, the more concrete (and the less abstract) s/he feels to it. Based on this perspective, some of students' mental process can be attributed to their tendency to make an unfamiliar idea more familiar. In this process, new knowledge is constructed based on existing knowledge. Thus, unknown (abstract) objects and structures are constructed based on existing mental structures.

2) Abstraction level as reflection of the process-object duality: The idea of reducing abstraction on the basis of process-object duality was generated by some theories of concept development in mathematics education (Beth and Piaget, 1966; Dubinsky, 1991; Sfard 1992; Thompson, 1985). According to process object duality, the mental process that leads from process conception to object conception is one mechanism, which is called reflective abstraction by Piaget. Piaget considered that it is reflective abstraction in its most advanced form that leads to the kind of mathematical thinking by which form or process is separated from content and that process themselves are converted in the mind of the mathematician, to objects of contents ( Dubinsky, 1991, p.98). Process conception implies that one regards a mathematical concept as a potential rather than an actual entity, which comes into existence upon request in a sequence of actions (Sfard , 1992). When one conceives of a mathematical notion as an object, this notion is captured as one 'solid' entity. Thus, it is possible to examine it from various points of views, to analyze its relationships to other mathematical notions and to apply operation on it. The abstraction level as the quality of the relationships between the 
object of thought and the thinking person is inter-related to the abstraction level as the reflection of the process-object duality. Because the more one works with an unfamiliar concept initially being conceived as a process, the more familiar one becomes with it and may proceed toward its conception as an object.

3) Abstraction level as the degree of complexity of the concept of thought: The assumption of this perspective is that: the more compound an entity is, the more abstract it is. So, when students should deal with compound objects that have not yet been fully constructed in their mind then they use as a handy tool: working with a less compound object. For instance, students reduce abstraction level by replacing a set with one of its elements. In this way, there is a connection between the interpretations for abstraction level as the degree of complexity of the concept of thought and abstraction as reflection of the process-object duality. For instance, 'the set concept' ties together with object conception and process conception. When the set concept is connected as an object, a person becomes capable of thinking about it as a whole without feeling an urge to go into details (Sfard, 1992), when conceived as a process, one deals with the elements of a set instead of with the set itself, that is: the process conception of the set concept.

\section{RESEARCH DESIGN}

The study used ethnographic design under qualitative approach in naturalistic setting to unpack the strategies of reduction of abstraction in learning abstract algebra. As research tools for this study, class observation, RME (Researcher in Mathematics Education) made test, interview guidelines were used.

\subsection{SAMPLE}

All the students enrolled in the undergraduate with major mathematics in B.Ed/undergraduate program, from different colleges of Kathmandu Valley (private and constituent colleges) were participants in the study for the purposes of field observations. All the participants had previously taken courses in Euclidean and non-Euclidean geometries, calculus, and real analysis. To select sample of the study, first I visited some private and constituent colleges. Having observations of some classes, interaction with students and teachers, studying students' written text and informal discussion on the basis of the written text from those colleges, I found, more or less students' learning styles, their difficulties regarding learning algebraic concepts, types of learners, teachers' delivered ways are similar. The key participants were selected by purposive sampling method. For that class observations, written tests (related to definition writing, to create examples and non-examples, proof writing), interviews were conducted. For interviewing students, issues were generated from preliminary analysis of the three sources of information: diaries, observation notes, and written tests. Later using all this information, I came to know the limitations and potentials of the students which provided the tentative ZPD (Zone of Proximal Development) of each student. From this group of students, I chose five students as key participants, who had given permission for full participation for the study. The key participants have been given pseudonyms.

\subsection{ANALYSIS AND INTERPRETATION}

As the analysis techniques and interpretation, the data, which were collected from class observations, field notes and interview notes related to the ways of reducing the level of abstraction were coded and used constant comparison and interpreted by Hazzan's framework.

Instantly some outstanding excerpts are:

Example-1

RME: Is $\mathrm{Z}_{4}$ subgroup of $\mathrm{Z}_{8}$ ?

Bahadur's line [60]: Yes! $\mathrm{Z}_{4}$ is subgroup of $\mathrm{Z}_{8}$. Because I can see 4 divides 8. Also I know, the order of Subgroup divides order of group.

Here, we can see coherently that the number 4 and 8 were familiar and meaningful to him and he was guided by the appearance of the number 4 and 8 and the fact that 4 divides 8 , ignoring the other details in the problem. It seems that he was hanged onto familiar mathematical entities, ignoring the meaning of the context described in that problem.

Example 2

International Journal of Research -GRANTHAALAYAH 
Sometimes students express logical arguments by using first person language. For instance

[262] RME: Does the function $\mathrm{f}: \mathrm{G} \rightarrow \mathrm{Z}_{4}$ form a homomorphism where $\mathrm{G}=\{1,-1, \mathrm{i}, \mathrm{i}\}$ ?

[263] Anu: First, I want to check the relation $\mathrm{f}(\mathrm{ab})=\mathrm{f}(\mathrm{a})$ 'f(b). Now if I can find for each... I mean consider, $\mathrm{f}(1)=[0]$, $f(i)=[1], f(-1)=[2], f(-i)=[3]$ Now I want to find does function ' $f$ ' preserve structure or not. So that $f(i(-1))=f(-$ i) $=[3]=[1]+[2]=f(i)+f(-1)$.

This is observed in Anu's line [263] where first person language reflected: student is working mentally for building concepts on her already existed mathematical schema in her mental structure. Indeed, the first-person language reflects the process conception in learning abstract algebra. This is less or more similar to finding of Hazzan's study (1999).

Example-3

Students focused on "symbol" or some mathematical entity to manage abstraction for their idiosyncratic understandings of abstract mathematical structure rather than the reflective thinking. Such strategy has been counter-productive in sense making and meaning making of mathematical abstraction. For example

[63] RME: What is the binary operation in group $\{1,2,3,4\}$ defined by the following group table?

\begin{tabular}{|l|l|l|l|l|}
\hline$?$ & 1 & 2 & 3 & 4 \\
\hline 1 & 1 & 2 & 3 & 4 \\
\hline 2 & 2 & 4 & 1 & 3 \\
\hline 3 & 3 & 1 & 4 & 2 \\
\hline 4 & 4 & 3 & 2 & 1 \\
\hline
\end{tabular}

[64] Sabi: I think there should be addition ' + ' but ...No, if ' + ' is binary operation then the identity element should be 'zero' but zero does not belong to in the given set. I think, it must be ' $x$ ' because in the table identity element is 'one'.

It took long time for her to determine first whether the operation in the given composition table was addition or multiplication. At last, she said the correct answer but in fact that was her guess because she was following the symbolic pattern rather than following the reflecting thinking. She already set in her mind that for Modular Arithmetic, when the binary operation will be ' + ' then there will be identity element is 'zero' and when the binary operation will be ' $x$ ' then there will be identity element is 'one'.

The answers of the research question were searched by testing of students' performance, clinical interviews on the basis of written texts, class observation, categories of students and reduction of abstraction strategies reference to Hazzan (1999). In learning abstract algebra, the abstraction depends on the degree of complexity of mathematical concepts. Sometimes, these degrees of complexity of mathematical concepts reduced by students' using their own idiosyncratic figures. Specially, students used idiosyncratic figures to learn definitions and proof writing of the theorem. Sometimes these figures were in the form of 'concept image' and sometimes in the form of 'concept definition'. I found, the idiosyncratic figures/diagrams which were developed/created by teacher were as the form of concept definition. Most often the idiosyncratic figures/diagrams used by students were as the form of concept image. Actually, in the learning process of advanced mathematics the concept images will move and gradually tends to concept definition. Use of idiosyncratic figures is more or less similar to Findell's (2001) study where he found in order to gain access to abstract ideas; the students relied on representations, metaphors, and other conceptual supports in order to manage the relation with unfamiliar abstraction.

\subsection{FINDINGS AND CONCLUSIONS}

This study made significant contributions to unpack the strategies of reduction of abstraction in learning abstract algebra. On the completion of analyzing aforementioned examples this study found:

One of the strategies of reduction of abstraction in learning abstract algebra is to make sense and meaning through previous experiences and existing knowledge an analogical creation of mental image like Bahadur's line [60], which is less or more similar to Hazzan's (1999) concept of making unfamiliar familiar. That is: new knowledge is constructed based on existing knowledge. Another student's strategy of reduction of abstraction in learning abstract algebra is to use first person language in course of doing mathematics by students as teachers do in the classroom for logical arguments. For instance, Anu's line [263]. To focus on "symbol" or some mathematical entity 
Ruma Manandhar (PhD), and Prof. Lekhnath Sharma (PhD)

to manage abstraction for their idiosyncratic understandings of abstract mathematical structure rather than the reflective thinking: for instance, Sabi's line [64]. To use students' own idiosyncratic figures to reduce the degrees of complexity of mathematical concepts. In context of Nepal, the conclusions continue with the suggestion that all these findings are distinct and fundamental aspects of teaching and learning of advanced mathematics in general and particularly in abstract algebra.

\section{SOURCES OF FUNDING}

This research received no specific grant from any funding agency in the public, commercial, or not-for-profit sectors.

\section{CONFLICT OF INTEREST}

The author have declared that no competing interests exist.

\section{ACKNOWLEDGMENT}

I am very much indebted to University Grants Commission (UGC), Nepal for providing me fund for this research and to the respondents as well as the teachers who were involved in the study in providing necessary data/information. Most of all I must thank my husband Pratap Pathak, who always encouraged me to be a researcher and supported me both emotionally and financially, and beloved sons: Sakar and Samriddha for their support.

\section{REFERENCES}

[1] Asiala, M., Brown, A., DeVries, D. J., Dubinsky, E.,Mathews, D., \& Thomas, K. (1996). A framework for research and curriculum development in undergraduate mathematics education. In J. Kaput, A. H. Schoenfeld, \& E. Dubinsky (Eds.), Research in Collegiate mathematics education, II (pp. 1-32). Providence, RI: American Mathematical Society.

[2] Asiala, M., Dubinsky, E., Mathews, D.M., Morics, S., \& Oktac, A. (1997). Development of students" understanding of cosets, normality, and quotient groups. Journal of Mathematical Behavior, 16, 241-309

[3] Beth, E. W. and Piaget, J. (1996). Mathematical Epistemology and Psychology. Dordrecht, The Netherlands: D. Reidel Publishing Company

[4] Brown, A., DeVries, D.J., Dubinsky, E., \& Thomas, K. (1997). Learning binary operations, groups and subgroups. Journal of Mathematical Behavior, 16, 187-239.

[5] Dubinsky, E. (1991). Reflective abstraction in advanced mathematical thinking. In D. Tall (Ed.),

[6] Advanced Mathematical Thinking, Kluwer Academic Press, pp. 95-123

[7] Dubinsky, E., Dautermann, J., Leron, U., \& Zazkis, R. (1994). On learning fundamental concepts of group theory. Educational Studies in Mathematics, 27(3), 267-305.

[8] Dubinsky, E.,\& Leron, U.(1994). Learning abstract algebra with ISETL. New York: Springer-Verlag

[9] Edwards, T. \& Brenton, L. (1999). An attempt to foster students' construction of knowledgduring a semester course in abstract algebra. The College Mathematics Journal, 30, 120-128

[10] Findell, B. (2001). Learning and understanding in abstract algebra. Unpublished Doctoral Dissertation, The University of New Hampshire Association of America

[11] Fukawa-Connelly, T. (2007). A tale of two courses: Teaching and learning undergraduate abstract algebra. Unpublished Doctoral Dissertation, The University of Maryland College ParkHirsch, J. (2008). Tracking changes in teaching and learning abstract algebra; Beliefs and ability to abstract. Unpublished Doctoral Dissertation, Columbia University USA

[12] Hazzan, 0. (1999). Reducing abstraction level when learning abstract algebra concepts.

[13] Educational Studies in Mathematics, 40, 71-90.

[14] Hirsch, J. (2008). Tracking changes in teaching and learning abstract algebra; Beliefs and ability to abstract. Unpublished Doctoral Dissertation, Columbia University USA 
[15] Leron, U., \& Hazzan, O. (1997). The world according to Johnny: A coping perspective in mathematics education. Educational Studies in Mathematics, 32(3), 265-292.

[16] Mingus, T. (2001). A case study of spiraling content and pedagogy through core courses for pre-service secondary mathematics teachers. In M. Ahmadi (Ed.), Reading in innovative ideas in teaching collegiate mathematics (pp. 191-213). Lanham, MD: University Press of America.

[17] Mitchel, M.C., \& White, P. (2007). Abstraction in Mathematics. Mathematics Education Research Journal, Vol 19, No 2, 20-9.

[18] Nardi, E. (1996). The Novice Mathematician's Encounter with Mathematical Abstraction: Tensions in Concept Images Construction and Formalization. Unpublished Doctoral Dissertation, University of Oxford. Linacre College.

[19] Nardi, E. (2008). Amongst Mathematicians: Teaching and learning Mathematics at University level. New York: Springer.

[20] Novotna, J., \& Hoch, M. (2008). How structure sense for algebraic expressions or equations is related to structure sense for abstract algebra. Mathematics Education Research

[21] Sfard, A. (1992). Operational origins of mathematical objects and the quandary of reification- The case of function. In E. Dubinsky and G.Harel (eds.), The Concepts of Function-Aspects of Epistemology and Pedagogy, MAA Notes.

[22] Thompson, P.W. (1985). Experience, problem solving, and learning mathematics:

[23] Considerations in developing mathematics curricula, in E.A. Silver (ed.), Teaching and Learning Mathematical Problem Solving: Multiple Research Perspective, Hillsdale, NJ, pp. 189-236. 